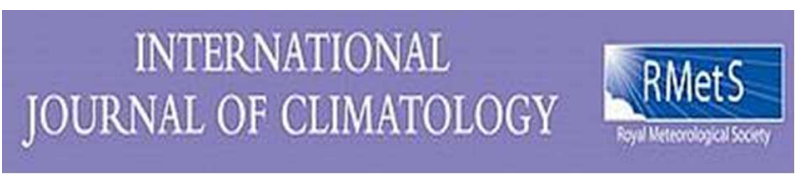

\title{
Relationship between weather conditions advantageous for the development of urban heat island and atmospheric macro-circulation changes
}

\begin{tabular}{|r|l|}
\hline Journal: & International Journal of Climatology \\
\hline Manuscript ID & JOC-17-0381.R2 \\
\hline Wiley - Manuscript type: & Research Article \\
\hline Date Submitted by the Author: & 12 -Feb-2018 \\
\hline Keywote List of Authors: & $\begin{array}{l}\text { László, Elemér; Magyar Tudomanyos Akademia Atommagkutato Intezet, } \\
\text { Section of Environmental and Earth Sciences } \\
\text { Salavec, Peter; Hungarian Meteorological Service, Unit of Aviation } \\
\text { Meteorology }\end{array}$ \\
\hline Country Keywords: & $\begin{array}{l}\text { urban heat island, atmospheric macro-circulation, wavelet transformation, } \\
\text { Habor-Morlet wavelet, teleconnections, time-series coherence }\end{array}$ \\
\hline &
\end{tabular}




\title{
Relationship between weather conditions advantageous for the development of urban heat island and atmospheric macro-circulation changes
}

\section{Short title:}

Relationship between urban heat island and macro-circulation changes

$$
\text { Elemér László }{ }^{1} \text { and Péter Salavec }{ }^{2, *}
$$

${ }^{1}$ Isotope Climatology and Environmental Research Centre, Institute for Nuclear Research, Hungarian Academy of Sciences 18/C. Bem tér, Debrecen, H-4026, Hungary

${ }^{2}$ Unit of Aviation Meteorology, Department of Forecasting, Hungarian Meteorological Service

1. Kitaibel Pál st., Budapest, H-1024, Hungary

* Corresponding author:

post: 15. Szabadság st., Tolmács, H-2657, Hungary

e-mail: salavec.p@met.hu

phone: +36309638306

\begin{abstract}
Urban heat island and climate change belong to two separate scientific fields within meteorology nowadays. Climate change, however, may affect the characteristics of urban heat island as well. Various atmospheric macro-circulation conditions determine the frequency of certain weather conditions at a given area, thus they influence the frequency of the occurrence of conditions advantageous for urban heat island development. In the present research the time series data of conditions advantageous for urban heat island (AMC Advantageous Meteorological Conditions) was determined in the case of Debrecen (Hungary) and similar patterns existing in the AMC time series were searched in those of NAO (North Atlantic Oscillation), EA (East Atlantic Oscillation), EA/WR (East Atlantic/Western Russia Pattern) and SCA (Scandinavian Oscillation) indices for the period between 1961 and 2010 using Gábor-Morlet wavelet transformations. Several significantly coherent oscillations were found. The occurrence frequency of advantageous meteorological conditions can be approximated from macro-circulation conditions in these periods, according to the concept of heat island. These estimations are consistent with the calculated AMC time series. This proves that there is some relationship between macro-circulation and heat island development. Based on the results, using seasonal and climate models the changes of urban heat islands at seasonal and climatic scales may become predictable.
\end{abstract}

\section{Keywords:}

urban heat island, atmospheric macro-circulation, wavelet transformation, Gabor-Morlet wavelet, teleconnections, time-series coherence 


\section{Introduction}

2 Nowadays the number of people living in urban areas is increasing. Since the

3 quality of life is significantly influenced by weather and adaptability to the conditions

4 determined by weather, studying meteorological features in urban environments is

5 increasingly important in an urbanized world (Kinney, 2008). Changes in the climate

6 or the atmospheric macro-circulation may influence the characteristics of heat islands

7 as well (Arnfield, 2003; McCarthy et al., 2010). This means that various macro-

8 circulation conditions increase the occurrence frequency of certain weather events

9 and reduce the occurrence frequency of others. As a result, the fact that frequency

10 changes of conditions advantageous for urban heat island could be associated with

11 changes in macro-circulation conditions could be regarded as hypothesis. Studying

12 these effects of climate change on heat island is increasingly interesting.

$13 \quad 1.1 \quad$ Aims

14 The primary aim of this study is to find the basics of a method which could be

15 useful to predict or estimate the changes of the characteristics of urban heat island

16 at a climatic time scale. This would be based on seasonal or climate model outputs

17 and similar patterns in the AMC and the macro-circulation time series would be de-

18 tected. Therefore we focus on similar patterns between a few indices (NAO - North

19 Atlantic Oscillation; EA - East Atlantic oscillation; SCA - SCAndinavian oscilla-

20 tion; EA/WR - East Atlantic/Western Russian oscillation) describing the oscillation 
21 of macro-circulation features influencing weather in the Carpathian Basin and the

22 time series of the occurrence frequency of conditions advantageous for urban heat

23 island development (AMC - Advantageous Meteorological Conditions) calculated

24 for Debrecen (Hungary).

25 The secondary aim of this paper is to verify that wavelet transformation is an

26 appropriate basis for the statistical model with which AMC changes could be pre-

27 dicted by analyzing the predicted time series of the macro-circulation indices of

28 climate models. In time periods when coherency between the time series of AMC

29 and macro-circulation indices is strong, the frequently occurring macro-synoptic

30 settings and the weather of the Carpathian Basin can be predicted on the basis of

31 macro-circulation conditions. The occurrence frequency of urban heat island can be

32 estimated on the basis of the conceptual model of heat islands.

\section{$33 \quad \mathbf{1 . 2}$ Qualitative theoretical bases}

34 Favorable conditions for urban heat island formation are windless nights with

35 clear skies or clear daytime weather, and the development of urban heat island is

36 also influenced by recent precipitation (Morris et al., 2001). Minor and slow changes

37 (in climatic or seasonal time scale) in meteorological elements are probably the

38 regional effects of climate change. As a result, it can be presumed that the frequency

39 of advantageous meteorological conditions for urban heat island is determined by

40 climate change (Molenaar et al., 2016; Sachindra et al., 2016).

41 Recent studies revealed that the morphological properties of the city as well as

42 the difference between the urban and rural boundary layer height may affect the 
43 urban heat island development (Theeuwes et al., 2017). Since the morphology of

44 Debrecen is given morphology aspects were ignored.

45 Several decades long oscillations can be found among those of atmospheric macro46 circulation systems, like the AMO (Atlantic Multi-Decadal Oscillation) phenomenon 47 (Dima and Lohmann, 2007). They influence the length and frequency of various 48 macro-circulation conditions, therefore it is worth studying whether changes in the 49 macro-circulation can be detected in the time series of the frequency of climatic 50 conditions advantageous for urban heat islands.

51 The macro-scale circulation systems in the temperate climate zones are directed

52 by action centres. These are low or high pressure atmospheric formations present 53 permanently or periodically, the only permanent is the Antarctic one. Their actual 54 state is in close connection with the wave features of the polar front, the behavior 55 of the Rossby waves and can determine fundamentally the weather conditions over 56 large areas and long periods. Their state can be described by atmospheric macro57 circulation indices that are anomalies of the pressure differences of certain selected 58 action centres.

59 Weather of Europe and the Carpathian Basin is influenced by several such action 60 centres. Permanent action centres include the Azores High and the Icelandic Low.

61 In winter, the Siberian High, while in summer, the Iranian Low occur due to ther-

62 mal reasons. In order to describe the pressure difference between the Azores High

63 and Icelandic Low, the NAO (North Atlantic Oscillation) index can be applied, the

64 positive anomaly of which suggest the strongly developed state of the two pressure

65 systems. At such times zonal flow is strong above the Atlantic Ocean and Europe. 
66 Negative AO (Arctic Oscillation) phase especially in winter suggests strong Siberian

67 High and weak Icelandic Low. At such times blocking conditions occur frequently

68 when meridional flow prevail instead of zonal one, and variably strong anticyclone

69 develops at locations different from the usual action centres and for shorter time

70 periods (generally for less than one month). In such conditions dry and very cold

71 winter or very hot summer occurs in Central and Eastern Europe. Location of the

72 blocking anticyclones is not random (Barriopedro et al., 2006), they appear often

73 above Great Britain and Scandinavia or above Central Europe in summer and the

74 East European Plain in winter. Macro-circulation indices describing blocking an-

75 ticyclones - similar to those describing the permanent and semi-permanent action

76 centres - exist, for example EA (East Atlantic Oscillation) and SCA (Scandinavian

77 Oscillation). The main variability with greatest amplitude in the time series of

78 EA and SCA are at the time scale of a few days or weeks which is the time scale of

79 blocking. However, oscillations with several months and years can also be identified.

$80 \quad 2$ Methods

2.1 Calculation of conditions advantageous for urban heat island development

83 Urban Heat Island Intensity (UHI) is defined as the daily maximum of hourly

84 differences between air temperatures measured at a height of $2 \mathrm{~m}$ in the city and

85 at a rural site. Three important factors (precipitation, wind speed, cloudiness)

86 were considered when the conditions for urban heat island formation were defined

87 (Kim and Baik, 2005). These factors were associated with threshold values (Ta- 
88 ble 1). According to László et al. (2016), four categories can be identified based

89 on the number of conditions met: $0,1,2$, and 3 standing for disadvantageous,

90 moderately disadvantageous, moderately advantageous and advantageous categories

91 respectively. The relative frequency of days within a year yielding favorable condi-

92 tions (category 3, when all three conditions met) for heat island development was

93 determined for each year. This time series constitute AMC data.

94 Definition of the threshold values in Table 1 was based on the empirical results of

95 studying the relationship between daily maximum UHI intensity measured on a local

96 scale and weather factors (see Bottyán et al., 2005; Landsberg, 1981; László et al.,

97 2016; Oke, 2002; Szegedi and Kircsi, 2003).

$98 \quad 2.2$ Relationship between AMC and variability of climate

100 Urban environments are exposed to natural climate variability and the oscilla-

101 tions of atmospheric processes. Such oscillations occur seasonally within a longer

102 time period the effects of which on temperature and precipitation can be estimated

103 relatively well for regions of the Earth. Climate change in a given region may in-

104 fluence temperature and precipitation in other, more distant areas as well. This is

105 caused by teleconnections. During the process energy from the climatically variable

106 source region is transported towards distant areas by the atmosphere. In this way,

107 natural climatic variability influences significantly the occurrence of extreme tem-

108 perature and precipitation events at a given location and time (Hurrell and Deser,

$1092010)$. 
110 Variability of atmospheric circulation is considered to be one of the most im-

111 portant factors the annual or decadal periods of which determine factors control-

112 ling meteorologically the urban heat islands, namely precipitation, wind speed and

113 cloudiness (Wilby et al., 1997). Relationship between calculated advantageous con-

114 ditions (AMC) and macro-circulation variability can be assumed, therefore indices

115 representing the atmospheric circulation system were applied in the study including

116 NAO, EA, SCA and EA/WR. Time series were obtained from the NOAA website

117 (http://cpc.ncep.noaa.gov/data/teledoc/telecontents.shtml).

\subsection{Description of the macrocirculation indices}

\subsubsection{North Atlantic Oscillation}

120 North Atlantic Oscillation is one of the most significant climatic phenomena de-

121 termining weather in the northern hemisphere in the Atlantic region over most of

122 the year. NAO index gives the oscillation of the pressure difference between the

123 Icelandic Low and the Azores High and also represents the strength of zonal winds

124 along northern mid-latitudes (Hurrell et al., 2001). In its strong positive phase

125 westerly winds carry warmer and cooler, wetter air into Europe in winter and sum-

126 mer respectively. It may also cause the development of cyclone bombs in extreme

127 cases (Sanders and Gyakum, 1980). Strong Icelandic cyclone activity results in wet

128 weather in Northern and Central Europe while in the lack of this cyclone activity

129 continental air flows towards the Mediterranean region from Eastern Europe taking

130 drier air with itself. 


\subsubsection{East Atlantic Oscillation}

132 East Atlantic Oscillation can be defined very similarly to NAO with pressure

133 centres located to the west of the British Isles and near the shores of Iberia and

134 North Africa. It represents subtropical connections of the changes in the temperate

135 zonal winds. In its positive phase weather warmer than average is expected for

136 entire Europe with wet weather in the north and in Scandinavia and dry weather in

137 Southern Europe (Barnston and Livezey, 1987). According to more recent research,

138 it determines the usual weather together with NAO in spite of that several decades

139 long oscillation of this index has greatest amplitude in the data series (Nesterov,

140 2010).

$141 \quad$ 2.3.3 Scandinavian Oscillation

142 Primary circulation centres of the Scandinavian Oscillation are located above the

143 Scandinavian region while secondary centres are located above Western Europe and

144 Eastern Russia. In the case of positive anomaly anticyclonic blocking situations

145 appear above Scandinavia and Western Russia resulting in more meridional flow

146 in place of zonal flow. At such conditions temperatures are lower than average

147 in Scandinavia. In Central Russia, Western, Central and Southern Europe, more

148 precipitation can be observed than the average while in Scandinavia the weather

149 becomes drier.

$150 \quad$ 2.3.4 East-Atlantic/Western-Russian Oscillation

151 Centres of the East-Atlantic/Western-Russian Oscillation are located in the North

152 Atlantic-Western European, Caspian-Western Russian and Northeastern Chinese 
153 regions. In the case of its positive phase, precipitation is less than average in Central

154 Europe but more than average in Eastern China. At the same time temperatures are 155 higher than average in Eastern Asia and lower in Western Russia and Northeastern 156 Africa (Ionita, 2014).

\subsection{Mathematical background}

In time-frequency space, Fourier-transformation converts a time series into a fre-

159 quency spectrum which loses the time dependent informations. The result of the

160 wavelet transformation contains both time and frequency dependent informations.

161 In this way it is useful to detect temporal variability of the amplitude of different

162 frequency oscillations in a time series. Cross wavelet transformation can highlight

163 time dependence of coherence between the two time series at different frequencies.

164 In essence, this method can be applied to study nonlinear processes, e.g. nonlinear

165 changes in a time series, or nonlinear connections between them. The greatest ben-

166 efit of the wavelet analysis is that the most changes types (for example permanent

167 and quasi-permanent oscillations, abrupt changes) in a time series can be identified

168 at once. Moreover, statistical connections between changes in two time series can be

169 identified using cross wavelet transformation. In the latter case, other methods (e.g.

170 cross-correlation analysis) are applicable only with certain restrictions and careful

171 interpretation of the results is needed: for example, nonlinear correlation analysis

172 methods can be useful, however, the distribution for determining significance cannot

173 be constructed always analytically. 
174 Heisenberg's uncertainty principle applies to the time-frequency space. The phase

175 cell volume is minimal in the case of Gábor-wavelet. This says that the best reso-

176 lution of the results in the time-frequency space can be earned using Gábor-wavelet

177 as the core function of the wavelet transformation.

178 The application of wavelet transformation became widespread in time series anal-

179 yses. The idea of Gábor (1946) was to use mathematical formulation of quan-

180 tum mechanics in electro-technical signal processing. The theory was completed by

181 Goupillaud et al. (1984) who proved the minimal phase cell property of the Gábor-

182 wavelet. Clearing of the steps of practical application of wavelet analysis was done by

183 Torrence and Compo (1998) taking sample time series from climatology and working

184 out statistical tests to study the significance of separating the obtained signs from

185 red and white noise. According to Grinsted et al. (2004), this method can be applied

186 in meteorology for example to detect coherent structures (teleconnections) analysing

187 variability of different meteorological characteristics of different areas caused by cli-

188 mate change. Examples of this application are the works by Duffy (2004); Farge

189 (1992); Lau and Weng (1995); Meneveau (1991); Meyers et al. (1993); Pal (2014);

190 Pal et al. (2016).

191 Processing of our data was performed using wavelet transformations with one

192 (CWT - Continuous Wavelet Transform) and two (XWT - Cross Wavelet Trans-

193 form) variables with Gábor-Morlet base (Gábor, 1946; Morlet, 1983). The results

194 of the CWT is shown in Fig. 1 and those of XWT in Fig. 2. The open source

195 MATLAB code from Grinsted et al. (2004) was applied to produce the figures. 
$196 \quad 3$ Results

\subsection{Analysis of teleconnections}

\subsubsection{North Atlantic Oscillation}

199 In the time series of the NAO index, three signs can be identified as significant

200 (Fig. 1, NAO). A significant variability with 2 to $3 \mathrm{yr}$ periodicity can be detected

201 between 2008 and 2012. This includes the negative phases of 2008, 2010 and 2012.

202 Blocking situations were more frequent in these three years.

203 A 8 to 10 year periodicity is present from the 1980s which is significantly strong

204 from 1987 to 1994. The increasing relative frequency of positive phases during this

205 period is recognizable as well as the disappearance of negative phases is evident in

206 the early 1990s and their reappearance after 1994.

207 Shortly after the appearance of the previous variability, an 11 to 12 yr oscillation

208 began to strengthen. This became significant after 1997 and remained so until

209 2012. This variability cannot be analyzed precisely because of the cone effect as

210 significance values can be distorted, i.e. enhanced artificially. A later study is

211 necessary to determine whether this periodicity remains permanent or not.

212 There is a cca. 4 yr periodicity at around 1985 to 1987 . It is not significant but it

213 is important as it contributes to a significant signal in the AMC-NAO cross wavelet

214 spectrum. This relates to a smaller but notable abrupt change in the NAO time

215 series as a strong minimum occurred after a $2 \mathrm{yr}$ positive dominance after which the

216 frequency of main oscillation increased. These NAO anomalies are because of the

217 macro-circulation which caused frequent windy weather in that period and the very 
218 cold winters of 1985 and 1987 in the Carpathian Basin. This sign will emerge later 219 also in the time series of other indices.

\subsubsection{East Atlantic Oscillation}

221 Two significant signs were found in the time series of the East Atlantic Oscillation

222 (Fig. 1, EA). First is a clear rise from 1950 to now. This is directed by step-like

223 increases of the average instead of a significant linear trend. Abrupt changes can

224 be identified, for example at 1977 when the negative dominance faded away and

225 positive and negative phases appear alternately, or at 2012 when negative phases

226 disappeared. Changes of periods greater than 6 to $7 \mathrm{yr}$ are missing in the studied 227 period.

228 The second sign is a 4 to 6 yr periodicity dominant between 1965 and 1980. In

229 that period, longer negative phases were interrupted with slightly positive ones in 230 every two years and every second negative phase (around 1967, 1972 and 1976) was

231 stronger than the others.

232 Later in this period, a 2 yr oscillation also appears which is significant around 233 1975. That was the first strong positive phase and actually the strongest ever until 2341998.

235 These signs disappear by 1980, then reappear around 1985 (although not signifi236 cantly) which means that the 4 yr periodicity is present at 1985 in this index, too. In 237 this case, a strong minimum is in 1984 after which the positive phases were weaker 238 than before until late 1987. 


\subsubsection{Scandinavian Oscillation}

240 Significant nonlinear changes were also found in the time series of Scandinavian 241 Oscillation (Fig. 1, SCA). Stronger positive phases dominated until 1980. These 242 changes are mainly shorter variabilities, but enhanced power spectrum densities are 243 visible also at longer periods.

2442 to $3 \mathrm{yr}$ periodicity is identifiable from 1968 to 1972 which then shifted to a 245 longer time period. This stronger sign then remains significant until 1977 with a 2463 to 5 yr period. Short negative phases interrupted the positive dominance of the 247 anomaly index.

248 A 2 to 5 yr variability appears with significantly enhanced power spectrum density 249 from 1998 to 2000. In this case, negative dominance emerged, then faded away.

250 Of the longer period variabilities, a 13 to $15 \mathrm{yr}$ periodicity is more enhanced from 251 the 1980s, although not significant. While it is not significant in the range inside of 252 the cone, it remains identifiable outside as well. If the variability remains present in 253 the next decade of years, the power spectrum density can increase further.

\section{$254 \quad 3.1 .4$ East-Atlantic/Western-Russian Oscillation}

255 There are two significant changes in the time series of the EA/WR index (Fig. 256 1, EA/WR). In one hand, a 4 to 6 yr periodicity appears in the late 1960s but it is 257 mainly out of cone. It is not visible by the naked eye in the time series data because 258 it is hidden by shorter changes of greater amplitudes.

259 Another is 2 to 4 yr variability present from 1980 to 1985 . Two strong minimums 260 are observable in late 1981 and early 1984. 
262 frequency and strength of negative phases are increased around 1950, 1960, 1970 and 2631980.

\subsubsection{Advantageous meteorological conditions for heat island}

268 windy weather.

269 Another significant sign is identified from 1997 to 2004 with 2 to 3 yr periodicity.

270 In this period, the relative frequencies of zonal and meridional macro-circulation

271 situations changed at several times. For example 1999 has mainly meridional situa-

272 tions but 2000 and 2001 have mainly zonal flows and then meridional flows became

273 more frequent from the winter of $2001 / 2002$.

274 Noticeable signs are a 4 to 6 yr periodicity around 1970 and an 8 to $10 \mathrm{yr}$ vari275 ability from 1970 to 1995. Although they are not significant, they are contributions 276 to some significant signs in the cross-spectra discussed in the following subsection.

\subsection{Results of cross wavelet analysis}

\subsubsection{North Atlantic Oscillation}

279 Using cross wavelet transformation of AMC and NAO time series, there can be 280 hardly any significant coherences identified (Fig. 2, AMC-NAO). The only one is 281 a 4 yr common variability from 1980 to 1987 which is barely significantly strong in 282 1985. The changes are in-phase. It indicates that in that period, changes of the 
283 Icelandic Low and Azores High directly affected the weather in the Carpathians so 284 that the advantageous meteorological conditions changed simultaneously. It is worth 285 remembering that a notable, but not significant increase was found in the NAO 286 CWT spectrum as mentioned in Section 3.1.1. Its role is that a cross-spectrum can 287 be significantly strong in a place where the two separate CWTs are not significant. 288 The second notable sign is an 8 to $10 \mathrm{yr}$ periodicity with about $45^{\circ}$ phase shift, 289 AMC changes follow NAO changes. This phase shift means a circa 1 yr difference.

\subsubsection{East Atlantic Oscillation}

291 A coherent pattern in the AMC-EA cross-spectrum (Fig. 2, AMC-EA) can be 292 detected from 1967 to 1975 with a periodicity of 4 to 6 yr. This is the case when 293 EA has a dominating variability with the same periodicity. In AMC time series, 294 this pattern can also identified although it is not significant. Its phase indicates a 295 somewhat less than 1 yr delay of AMC to EA.

296 Another significant sign is a 3 to 6 yr oscillation around 1985. The CWT of both 297 the AMC and EA time series show increased power spectrum density at this time 298 and frequency range. Due to the similar definitions of the EA and NAO indices, their 299 time series can be correlated. Therefore it can be assumed that the same macro300 scale effects caused both the AMC-NAO and the AMC-EA coherences. Physically, 301 it can be related to the abrupt changes occurring in the time series at around 1985 302 which can be related to the very cold winter periods of 1985 and 1987, and the 303 unusually windier weather in that period in the Carpathian basin. The phase shift 304 indicates that the decreasing of AMC precedes that of EA. NAO decreasing, as it 305 is synchronous with the AMC decrease, also precedes the EA decrease. This means 
306 that when the Icelandic cyclone activity becomes weaker, the relative frequency 307 of British blocking situations begin to increase. At the beginning of this period, 308 northwesterly flow regimes dominated the weather of Central Europe (sometimes 309 called as half-blocking situations) in which the average wind is the strongest.

\section{$310 \quad 3.2 .3 \quad$ Scandinavian Oscillation}

311 In the case of AMC-SCA cross wavelet spectrum (Fig. 2, AMC-SCA), four dif312 ferent significantly coherent variabilities can be detected. The first two are a $2 \mathrm{yr}$ 313 variability before 1970 and a 4 yr one after 1970 . These match to the significant 2 314 to 5 yr variability of SCA from 1968 to 1977, but AMC wavelet spectrum density 315 is only increased in this two ranges. The phase shift indicates SCA changes with 316 about a quarter period later than AMC changes.

317 Next significant sign is a 3 to 4 yr periodicity from 1980 to 1985 . A sign found in 318 the SCA spectrum near this range is not significant and changes of AMC precede 319 those of SCA. Thus, existence of any relation of this sign with the mentioned events 320 of 1985 to 1987 is less likely.

321 Lastly, an around 3 yr variability is found from 1995 to 2000 . The changes are 322 in-phase, but AMC changes get significant after 2000, when SCA changes fade.

323 In this period, changes of relative occurrence frequency of Scandinavian blocking 324 anticyclones might affect directly the occurrence frequency of the advantageous me325 teorological conditions. In the Scandinavian blocking macro-circulation situations, 326 however, the Carpathian basin can have anticyclonic and cyclonic weather depend327 ing on the strength and the spatial coverage of the anticyclone: the Mediterranean 328 cyclones can go over the Carpathian basin or may remain further to the south. 
330 The AMC-EA/WR cross wavelet spectrum indicates three significant coherence 331 patterns exactly matching with increased AMC variability patterns. The first two 332 are present also in the EA/WR time series.

333 A 4 to 6 yr periodicity is identifiable from 1965 to 1970 . The phase shift changes 334 with the time period indicating a $3 \mathrm{yr}$ delay of AMC to EA/WR independently of 335 the time period.

336 A 3 to 4 yr periodicity is significant from 1980 to 1987. In the later part of this 337 range, EA/WR variability fades. The phase shift indicates the opposite direction of 338 changes.

339 The third sign found is a 2 to $3 \mathrm{yr}$ coherence from 1997 to 2003 which is an in340 phase common variability. This is identifiable as significant in the AMC series, but 341 the power spectrum density in the wavelet transform of AMC time series is not high.

\subsection{Discussion}

343 The above results are the signs of possible common variabilities of the macro-

344 circulation indices and the frequency of the meteorological conditions advantageous

345 for urban heat island development. To prove the connections, explanation of these

346 with real meteorological events is needed. Some explanations were made in the previ347 ous subsections at some of the changes found in a qualitative manner. "Naked eye" 348 analysis of the 3 month running averaged index datasets (Barnston and Livezey, 349 1987) were made in order to identify (when possible) the signs with apparent changes 350 in the time series. More detailed analysis of the real weather and its relation with the 

macro-circulation indices and the advantageous conditions for heat island develop-

352 ment may be helpful to identify the physical connections between the phenomena.

353 In this section we summarize the signals found, and explain them with the real 354 meteorological processes and their influence on urban heat island.

355 Significantly high power spectrum density in the CWT of NAO and moderate in 356 the XWT of it with AMC indicates that the changes of the occurrence frequency 357 of weather conditions advantageous for urban heat island development show some 358 similar patterns, meaning that the urban heat island development can follow NAO 359 index changes. The $45^{\circ}$ phase shift indicates that the changes in the advantageous 360 meteorological conditions follow changes in NAO by 1 year. In the AMC dataset, 361 a significant $4 \mathrm{yr}$ periodicity is visible at around 1985. A slight increase in NAO 362 dataset can also be detected which makes a significant increase in the XWT of 363 NAO. The changes are in phase meaning that in the mid 1980s, the NAO and the 364 AMC follow each other tightly. In the Carpathian Basin, the 1985 and 1987 winters 365 produce extreme cold weather with frequent snow storms which are more frequent 366 at low NAO, resulting in that urban heat island development is less possible because 367 of the wind and cloudiness. When Scandinavian oscillation rises, anticyclonic influ368 ence increases in the Carpathian Basin. In such periods, conditions advantageous 369 for urban heat island development becomes more frequent, thus the XWT of SCA 370 against AMC also rises significantly. These were found with 2 to 4 yr periods. The 371 EA/WR dataset shows a significant variability with 2 to $4 \mathrm{yr}$ period in the early 372 1980s which doesn't coincide with the 4 yr periodicity in the AMC later. A smaller 373 increase in EA/WR is found after 2000 with 2 to 4 yr periodicity. The significant in- 
374 crease in AMC there makes a significant signal in XWT. The pattern in the EA/WR 375 index resulted in the greater precipitations in 1999 and the dry weather in 2001. In 376 accordance with this, AMC frequency also rises in this period.

377 The above results prove that the variability of atmospheric circulation deter378 mines the distribution of precipitation and temperature in both time and space. It 379 also determines the pattern of climatic elements, so it has influences on changes of 380 conditions advantageous for heat islands in time in the studied time periods. As a 381 result of the cross wavelet transformation, significant common periods were detected 382 between the oscillation indices of macro-circulation and the frequency time series 383 of AMC. Therefore teleconnections between these macro-circulation processes and 384 urban heat island can be identified. Presented results support that wavelet analysis 385 is a useful tool in time series analysis. Apart from these, common periodicities and 386 phase connections were exposed by comparing time series using cross wavelet trans387 formation. This result proves that non-linear changes of conditions advantageous for 388 urban heat island could be influenced significantly by certain changes of large-scale 389 atmospheric circulations.

\section{Conclusions}

391 Dynamics of large-scale atmospheric circulation determines fundamentally types 392 of flow (zonal, meridional) thus also temperature and precipitation anomalies. The 393 changes in macro-circulation over longer periods of time are determined by pres394 sure difference anomalies between low and high pressure centres, the measurement 395 values of which are macro-circulation oscillation indices. Among them, oscillation 
indices having greatest influence on the weather of the Carpathian Basin were se-

397 lected (NAO, EA, EA/WR, SCA). Significant common variability between these

398 indices and the frequency time series of weather conditions advantageous for urban

399 heat island development was detected. North Atlantic and East Atlantic Oscilla-

400 tions represent the strength of zonal winds that influences meteorological parameters

401 controlling urban heat island development. In the case of more marked zonal flow,

402 advantageous conditions occur less frequently and temperatures are lower while pre-

403 cipitation is greater than the average around Debrecen. EA/WR and SCA represent

404 meridional flow and more frequent occurrence of blocking conditions when mostly

405 anticyclone dominates in Northern Europe. In such weather situations the occur-

406 rence frequency of conditions for urban heat island development is significantly high.

407 Furthermore, in the identified periods - showing significantly similar variability -

408 temperature anomaly is positive while the amount of precipitation is significantly

409 smaller than in the average years. This is proved by the XWT of EA in which we

410 can identify the 4 to 5 yr periodicity after 1985 when EA were in negative phase

411 suggesting cyclonic weather in the Carpathian Basin. The decrease of EA index

412 follows that of AMC frequency which is shown by the ca. $270^{\circ}$ phase shift.

413 Applying wavelet transformation on the time series of AMC and macro-circulation

414 oscillation indices enable the detection of links between them. The analysis of the

415 regional weather in the Carpathian Basin was not needed, it may be only an extra

416 control over the theory. The results of this study show that for predicting changes in

417 the characteristics of urban heat islands, the use of seasonal and climate models able

418 to simulate the changes in macro-circulation is sufficient. Using wavelet transform 
419 to the model's output may show coherence patterns similar to those presented here.

420 In such cases, the characteristics of the urban heat island may expected to be similar

421 as well. In this way, urban heat island features become predictable by passing the 422 prediction of regional changes which would lead to an increase of uncertainties.

423 Therefore we hypothesize that this method can decrease the uncertainties in the

424 prediction of changes of urban heat island characteristics.

425 Further studies of past conditions in other cities are needed to increase the experi426 ence with finding more links between urban heat island and macro-circulation. As a 427 next step, some cataloging of the found links would be required to organize their oc428 currence time period, the places where the link can be found, the macro-circulation 429 indices that link with the AMC time series, the state of, and the changes in, the 430 macro-circulation and in the urban heat island characteristics or other features. In

431 this way, merging common features together, a database can be made that may ease 432 the determination of changes in urban heat island characteristics when coherence 433 patterns from climate models are calculated.

\section{Acknowledgements} 436 on this study.

437 Special thanks to colleagues at the Department of Meteorology, Eötvös Loránd 438 University, Budapest, Hungary, namely Ádám Leelőssy, Zsuzsanna Soósné Dezső 439 and Tamás Weidinger for their advices on this article. We are also thankful to 
440 Ádám Leelőssy and Richard William McIntosh (University of Debrecen) for their

441 help in improving the grammar of the text.

442 The research was supported by the European Union and the State of Hungary,

443 co-financed by the European Regional Development Fund in the project of GINOP-

444 2.3.2.-15-2016-00009 'ICER'.

\section{References}

446 Arnfield AJ. 2003. Two decades of urban climate research: a review of turbulence, 447 exchanges of energy and water, and the urban heat island. Int. J. Climatol. 23: 448 1-26. doi:10.1002/joc.859.

449 Barnston AB, Livezey RE. 1987. Classification, Seasonality and Persistence of Low450 Frequency Atmospheric Circulation Patterns. Mon. Wea. Rev. 115: 1083-1126. 451 doi:10.1175/1520-0493(1987)115<1083:CSAPOL>2.0.CO;2.

452 Barriopedro D, García-Herrera R, Lupo AR, Hernández E. 2006. A Climatology of 453 Northern Hemisphere Blocking. J. Climate 19: 1042-1063. doi:10.1175/JCLI3678. 4541.

455 Bottyán Zs, Kircsi A, Szegedi S, Unger J. 2005. The relationship between built-up 456 areas and the spatial development of the mean maximum urban heat island in 457 Debrecen, Hungary. Int. J. Climatol. 25: 405-418. doi:10.1002/joc.1138.

458 Dima M, Lohmann G. 2007. A Hemispheric Mechanism for the Atlantic Multidecadal 459 Oscillation. J. Climate 20: 2706-2719. doi:10.1175/JCLI4174.1.

460 Duffy DG. 2004. The Application of Hilbert-Huang Transforms to Meteorological 461 Datasets. J. Atmos. Ocean. Technol. 21: 599-611. doi:10.1175/1520-0426(2004) $462 \quad 021<0599:$ TAOHTT $>2.0 . \mathrm{CO} ; 2$.

463 Farge M. 1992. Wavelet Transforms and their Applications to Turbulence. Ann. Rev. 464 Fluid Mech. 24: 395-458. doi:10.1146/annurev.fl.24.010192.002143.

465 Goupillaud P, Grossmann A, Morlet J. 1984. Cycle-octave and related transforms 466 in seismic signal analysis. Geoexploration 23: 85-102. doi:10.1016/0016-7142(84) $467 \quad 90025-5$.

468 Grinsted A, Moore JC, Jevrejeva S. 2004. Application of the cross wavelet transform 469 and wavelet coherence to geophysical time series. Nonlin. Proc. Geophys. 11: 561470566.

471 Gábor D. 1946. Theory of Communication. J. IEEE Radio Comm. Eng. 93: 429472 441. doi:10.1049/ji-3-2.1946.0074. 
473 Hurrell JW, Deser C. 2010. North Atlantic climate variability: The role of the North 474 Atlantic Oscillation. J. Marine Sys. 79: 231-244. doi:10.1016/j.jmarsys.2009.11. $475 \quad 002$.

476 Hurrell JW, Kushnir Y, Visbeck M. 2001. The North Atlantic Oscillation. Science 291: 603-605. doi:10.1126/science.1058761.

Ionita M. 2014. The Impact of the East Atlantic/Western Russia Pattern on the Hydroclimatology of Europe from Mid-Winter to Late Spring. Climate 2: 296309. doi:10.3390/cli2040296.

481 Kim YH, Baik JJ. 2005. Spatial and Temporal Structure of the Urban Heat Island in Seoul. J. Appl. Meteorol. 44: 591-605. doi:10.1175/JAM2226.1.

483 Kinney PL. 2008. Climate Change, Air Quality, and Human Health. Am. J. Preventive Medicine 35: 459-467. doi:10.1016/j.amepre.2008.08.025.

485 Landsberg HE. 1981. The Urban Climate. International Geophysics Series 28. Academic Press, New York; London; Toronto; Sydney; San Francisco.

Lau WKM, Weng H. 1995. Climate Signal Detection Using Wavelet Transform: How to Make a Time Series Sing. Bull. Am. Meteorol. Soc. 76: 2391-2402. doi: 10.1175/1520-0477(1995)076<2391:CSDUWT>2.0.CO;2.

László E, Bottyán Zs, Szegedi S. 2016. Long-term changes of meteorological conditions of urban heat island development in the region of Debrecen, Hungary. Theor. Appl. Climatol. 124: 365-373. doi:10.1007/s00704-015-1427-9.

McCarthy MP, Best MJ, Betts RA. 2010. Climate change in cities due to global warming and urban effects. Geophys. Res. Lett. 37: doi:10.1029/2010GL042845.

Meneveau C. 1991. Analysis of turbulence in the orthonormal wavelet representation. J. Fluid Mech. 232: 469-520. doi:10.1017/S0022112091003786.

Meyers SD, Kelly BG, O'Brian JJ. 1993. An Introduction to Wavelet Analysis in Oceanography and Meteorology: With Application to the Dispersion of Yanai Waves. Mon. Wea. Rev. 121: 2858-2866. doi:10.1175/1520-0493(1993)121<2858: AITWAI $>2.0 . \mathrm{CO} ; 2$.

Molenaar RE, Heusingveld BG, Steeneveld GJ. 2016. Projection of rural and urban human thermal comfort in The Netherlands for 2050. Int. J. Climatol. 36: 17081723. doi:10.1002/joc. 4453 .

Morlet J. 1983. Sampling Theory and Wave Propagation. in Issues in Acoustic Signal and Image Processing and Recognition, edited by C.H. Chen, no. 1 in NATO ASI Series, pp. 233-261. Springer, Berlin; Heidelberg.

Morris CJG, Simmonds I, Plummer N. 2001. Quantification of the Influences of Wind and Cloud on the Nocturnal Urban Heat Island of a Large City. J. Appl. Meteorol. 40: 169-182. doi:10.1175/1520-0450(2001)040<0169:QOTIOW >2.0.CO;2. 
510 Nesterov ES. 2010. East Atlantic oscillation of the atmospheric circulation. Meteorol. Gidrol. 34: 794-800. doi:10.3103/S1068373909120048.

512 Oke TR. 2002. Boundary Layer Climates. Routledge, London; New York.

513 Pal S. 2014. Monitoring Depth of Shallow Atmospheric Boundary Layer to Com514 plement LiDAR Measurements Affected by Partial Overlap. Remote Sensing 6: 515 8468-8493. doi:10.3390/rs6098468.

516 Pal S, De Wekker SJF, Emmitt GD. 2016. Investigation of the Spatial Vari517 ability of the Convective Boundary Layer Heights over an Isolated Moun518 tain: Cases from the MATERHORN-2012 Experiment. 55: 1927-1952. doi: 519 10.1175/JAMC-D-15-0277.1.

520 Sachindra DA, Ng AWM, Muthukumaran S, Perera BJC. 2016. Impact of climate 521 change on urban heat island effect and extreme temperatures: a case-study. Quart. 522 J. Roy. Meteorol. Soc. 142: 172-186. doi:10.1002/qj.2642.

523 Sanders F, Gyakum JR. 1980. Synoptic-Dynamic Climatology of the "Bomb". Mon. 524 Wea. Rev. 108: 1589-1606. doi:10.1175/1520-0493(1980)108<1589:SDCOT>2. $525 \quad 0 . \mathrm{CO} ; 2$.

526 Szegedi S, Kircsi A. 2003. The effects of the synoptic conditions on development 527 of the urban heat island in Debrecen, Hungary. Acta Climatol. Chorol. 36-37: $528 \quad 111-120$.

529 Theeuwes NE, Steeneveld GJ, Ronda RJ, Holtslag AAM. 2017. A diagnostic equa530 tion for the daily maximum urban heat island effect for cities in northwestern 531 Europe. Int. J. Climatol. 37: 443-454. doi:10.1002/joc.4717.

532 Torrence C, Compo GP. 1998. A Practical Guide to Wavelet Analysis. Bull. Am. 533 Meteorol. Soc. 79: 61-78. doi:10.1175/1520-0477(1998)079<0061:APGTWA $>2$. $534 \quad 0 . \mathrm{CO} ; 2$.

535 Wilby RL, O'Hare G, Barnsley N. 1997. The North Atlantic Oscillation and 536 British Isles climate variability, 1865 to 1996. Weather 52: 266-276. doi: $537 \quad 10.1002 / j .1477-8696.1997 . t b 06323 . x$. 
Table 1: Criteria for conditions advantageous for urban heat island development. Listed elements cannot exceed the value associated with them over the given day. The time series associates the given years with the ratio of days in the suitable category to the total number of days in the year.

\begin{tabular}{cc}
\hline Meteorological element & Threshold value \\
\hline Daily precipitation & $2 \mathrm{~mm}$ \\
Highest wind velocity & $3 \frac{\mathrm{m}}{\mathrm{s}}$ \\
Highest cloud cover & 5 oktas \\
\hline
\end{tabular}


AMC

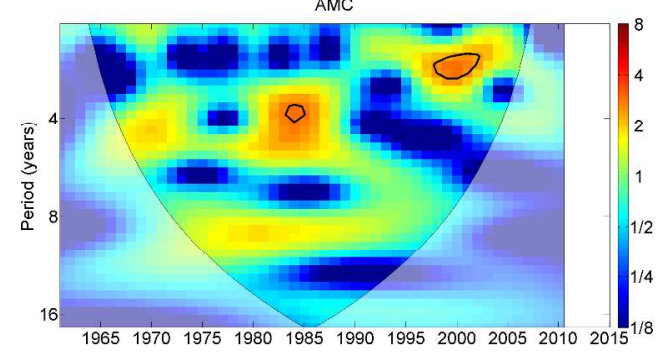

NAO

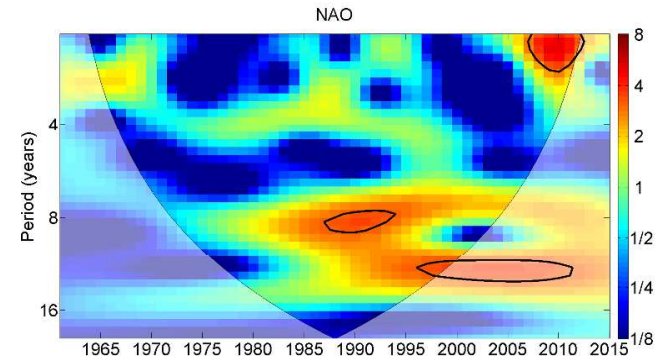

EAMR

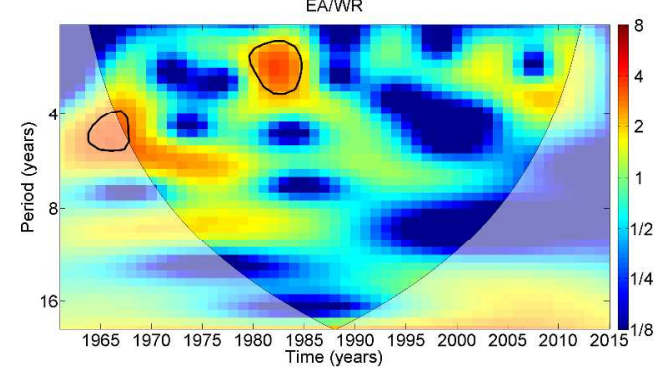

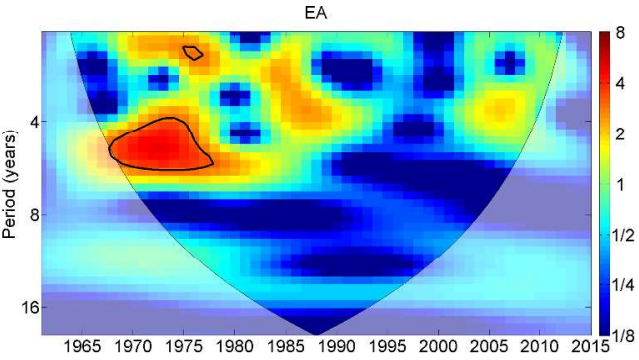
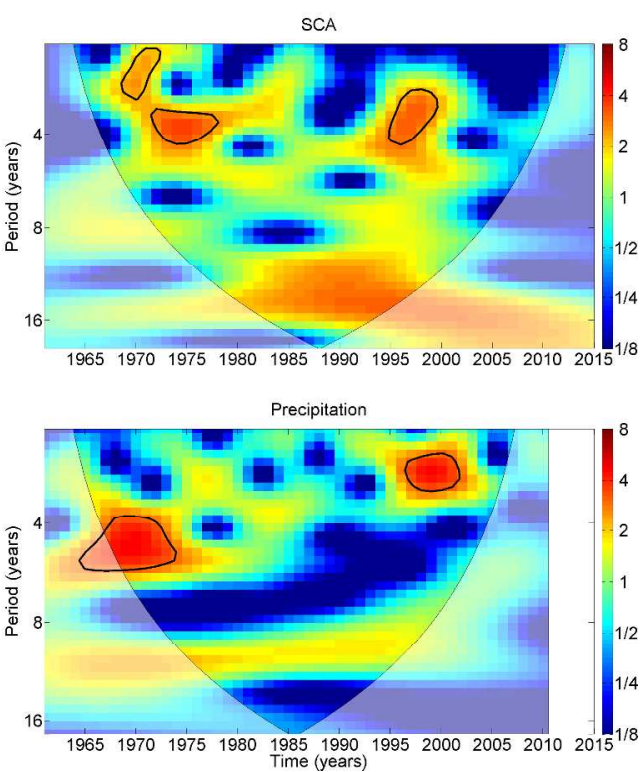

Figure 1: Results of the continuous wavelet transform. Shades denote the dimensionless CWT power spectrum density. High values of it in a some time interval ( $x$ axis) with some periodicity ( $y$ axis) show that the amplitude of a signal with that periodicity emerges from noise in those years. Black contour denotes the $5 \%$ significance level against red noise. The area where edge effect influence distorts the picture is shown in lighter shades.

$$
1184 \times 1032 \mathrm{~mm}(72 \times 72 \mathrm{DPI})
$$



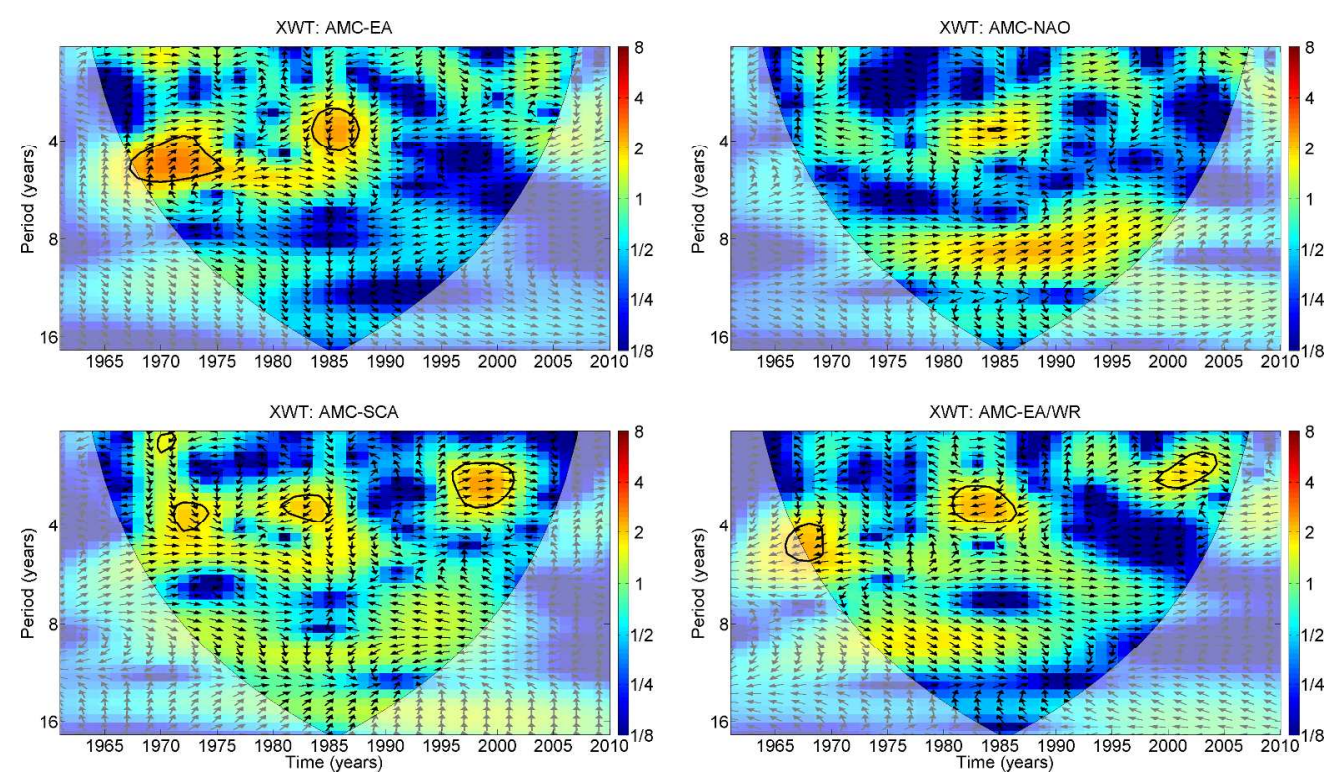

Figure 2: Results of the cross wavelet. Shades denote the dimensionless XWT power spectrum density. Black contour denotes the $5 \%$ significance level against red noise. The area where edge effect influence distorts the picture is shown in lighter shades. Arrows denote the phase shift between the time series, pointing to the right if they are in-phase.

$1184 \times 682 \mathrm{~mm}(72 \times 72 \mathrm{DPI})$ 